\title{
Digital ageing in Europe: a comparative analysis of Italian, Finnish and Swedish national policies on eHealth
}

\author{
Heli Valokivi ${ }^{1 \star}$ (D), Simone Carlo ${ }^{2}$, Elin Kvist $^{3}$ (D) and Marjo Outila ${ }^{4}$ (C) \\ ${ }^{1}$ Faculty of Humanities and Social Sciences, Department of Social Sciences and Philosophy, University of \\ Jyväskylä, Jyväskylä, Finland, ${ }^{2}$ Faculty of Political and Social Sciences, Università Cattolica del Sacro Cuore, \\ Milan, Italy, ${ }^{3}$ Department of Sociology, Umeå University, Umeå, Sweden and ${ }^{4}$ Faculty of Social Sciences, \\ University of Lapland, Rovaniemi, Finland \\ ${ }^{*}$ Corresponding author. Email: heli.valokivi@jyu.fi
}

(Accepted 6 May 2021; first published online 8 July 2021)

\begin{abstract}
Ageing Europeans are today healthier than previous generations and often manage to live independently up to a high age. The proportion of people 80 years of age and older has increased significantly, and with high age the risk of multi-illness and dementia increases. Strong urbanisation processes have changed the demographic structure in rural areas, and young women and men have migrated towards the urban areas to study and work, while older persons have remained behind. This demographic challenge of increasing numbers of persons older than 80 years with care needs living in remote rural areas has become a major European social problem. In tackling this dilemma, many European countries have high expectations for eHealth, digitalisation and welfare technology. In this comparative study of policy debates in Italy, Finland and Sweden, we analyse how - between 2009 and 2019 - the issues of eHealth have been articulated in national and regional policies of the three countries with deep differences in terms of digitalisation and health systems, but with similar ageing populations. We identify in the documents three core topics - the role of technology, the rural issue and responsibility for care. These topics are treated in the documents with differences and similarities between the three countries. Beyond the differences and similarities, the documents reveal both a certain techno-enthusiasm about the role of eHealth in the life of the older adults as well as a limited understanding of the complexity (relationally as well as spatially) of the digital landscape of caring for older adults.
\end{abstract}

Keywords: eHealth; ageing policies; digitalisation; digital landscape of care; qualitative comparison

\section{Introduction}

\section{eHealth}

Europe's health and care systems face serious challenges such as ageing citizens with complex care needs, health workforce shortages and continuing urbanisation

(C) The Author(s), 2021. Published by Cambridge University Press. This is an Open Access article, distributed under the terms of the Creative Commons Attribution licence (https://creativecommons.org/licenses/by/4.0/), which permits unrestricted re-use, distribution, and reproduction in any medium, provided the original work is properly cited. 
(European Commission, 2018). Public spending on health and long-term care is expected to continue to rise in all European Union (EU) member states (European Commission and Economic Policy Committee, 2016). In The State of Health in the EU report (European Commission, 2017), it was concluded that the health-care systems need fundamental rethinking and innovative solutions to become more resilient, accessible and effective in providing quality care in Europe. Digital solutions for health and care, referred to as eHealth, are envisioned to have the potential to increase the wellbeing of millions of citizens and to change radically the way health and care services are provided (European Commission, 2018). The benefits of increased eHealth are multifaceted, and eHealth supports continuity of care across borders, promotes health and prevents disease, supports the transition of the health system to new care models, i.e. more centred on people's needs, and enables a shift from hospitalcentred systems to more community-based and integrated care structures. However, there have also been concerns regarding technology's availability and usability, especially with older age groups (Heart and Kalderon, 2013; Airola et al., 2020).

Even though the expectations are high for the potential of eHealth across Europe, EU member states differ greatly with respect to their welfare regimes (Kvist, 2012) and care systems. Lutz (2016) describes a spectrum of European care regimes. On one end are the traditional care regimes linked to conservative gender regimes, often exemplified by Germany and the southern European countries, while on the other end we have the more equal care and gender regimes, such as the Scandinavian countries (Lutz, 2016). Even though placing European countries in clusters or regimes is problematic, some scholars agree that it is possible to identify different European care regimes (Anttonen and Sipilä, 1996; Daly, 2001; Bettio and Plantenga, 2004; Lister et al., 2007).

Studies on eHealth have shown the benefits of the technology used in care and promoting wellbeing. Our focus in this article is on older adults, and technology has proven to be beneficial in supporting health assessment and care, and overall wellbeing in this population (e.g. Bradford et al., 2018). However, problems associated with eHealth are connected to issues like lost privacy and the frivolous use of the devices (e.g. Cook et al., 2016; Lie et al., 2016), and monitoring devices also risk threatening the good relationship between carers and those being cared for, i.e. carers might get more information than they need or more information than the person is willing to share (Pols, 2017). In this article, eHealth refers to the technological solutions designed to be used in elderly care, for example, solutions to promote living at home, remote solutions and older adults' self-care. eHealth is close to other concepts such as gerontechnology (Delello and McWhorter, 2017), assistive technology (Fischer et al., 2014), mHealth (Spann and Stewart, 2018), telecare (Bentley et al., 2018) and welfare technology (Östlund et al., 2015). Our aim is to analyse and compare Italian, Finnish and Swedish policy documents in terms of how eHealth, digitalisation of care, older adults, sparsely populated areas and care responsibilities are talked about, and what kinds of digital landscapes of care are created as well as what consequences this has on our perception of older people and care. 


\section{Conceptual framework: digital landscape of care}

To understand the possible similarities and differences in Italian, Finnish and Swedish eHealth policies, we will use the concept of digital landscape of care. The concept of digital landscape of care (Milligan and Wiles, 2010; Lindberg and Carlsson, 2018) is used in this article to analyse how eHealth is understood as part of older adults' lives and care. The concept refers 'to the complex embodied and organizational spatialities that emerge from and through the relationships of care' (Milligan and Wiles, 2010: 740). Milligan and Wiles' (2010: 739) concept is comprehensive, including socio-structural processes and structures, experiences and practices of care, which include issues like support, services, ethics, morals, responsibilities and the spatial politics of care.

Lindberg and Carlson (2018) have directed Milligan and Wiles' concept towards eHealth, and they talk about a digital landscape of care. Lindberg and Carlson (2018) have studied 'virtual health rooms' and the ideological beliefs that are included in the introduction of digital care in sparsely populated areas in Sweden. They found that eHealth is often welcomed with optimism, and it is believed to improve the quality of care, reduce care costs and encourage older people to take care of themselves. Lindberg and Carlson (2018) point out that the discourses of patient participation, active ageing and rurality as a problem are part of the eHealth talk, and that such discourses need to be assessed critically.

Studies on the use of technology in elder-care have examined older adults' perceptions, attitudes, acceptance and learning of technologies (Peek et al., 2014; Claes et al., 2015: Tsai et al., 2017), technologies' effectiveness and feasibility (Khosravi and Ghapanchi, 2016; Barbosa Neves et al., 2017), and barriers and enablers to technology use (Bentley et al., 2018; Spann and Stewart, 2018). Research results have indicated the positive effects of technology use in old age in terms of reduced falls (Tchalla et al., 2012), improved health management (Bradford et al., 2018), increased independence and safety (Stokke, 2016), reinforced social relationships, reduced social isolation, social and spatial barriers, and loneliness (Winstead et al., 2013; Chen and Schulz, 2016; Barbosa Nevese et al., 2017; Bradford et al., 2018; Antunes et al., 2019), and decreased need for institutional care (Riikonen et al., 2010). Technology use can create and enhance ties with friends and family (Barbosa Neves et al., 2017; Bradford et al., 2018), give pleasure (Østensen et al., 2017), and enable older people to produce knowledge and exchange it with others (Delello and McWhorter, 2017). In health care, technology has been proven to be useful in managing health issues or coping with symptoms (Kerssens et al., 2015; Bradford et al., 2018) and as a medium for therapy (Choi et al., 2014), in rehabilitation (Shulver et al., 2017), and in health status assessment, monitoring and selfmanagement (Bond and Worswick, 2015; Brown et al., 2015). Technology has also proven to be beneficial for homebound people (Mitzner et al., 2017) by providing alternative ways for people to connect with other people (Kilpeläinen and Seppänen, 2014; Hasan and Linger, 2016; Tsai et al., 2017).

However, negative outcomes of the use of technology have also been identified, such as loss of trust, safety and privacy (Lie et al., 2016; Yusif et al., 2016; Pols, 2017), stigmatisation and increased dependency (Bentley et al., 2018), concerns related to costs (Spann and Stewart, 2018), and the uselessness and unsuitability 
of certain technologies (Cook et al., 2016). Also, negative outcomes such as losing the possibility to meet physically other people (Frennert et al., 2013; Currie et al., 2015; Shulver et al., 2017) and care professionals in person (Zwijsen et al., 2011; Kim et al., 2017) and concerns about the way surveillance changes people's way of life (Bradford et al., 2018) have been reported.

\section{Objectives and rationale for the work}

In this article, three EU member states - Italy, Finland and Sweden - function as our cases in illustrating different governments' approaches to eHealth, with a special focus on the ageing European citizen in the rural context. Both Finland and Sweden belong to the more equal care and gender regimes, while Italy is expected to have a more traditional care regime linked to a conservative gender regime. We are interested in how these countries differ in their eHealth policy approaches and how notable these differences are. The objective of the study is to contribute data for the analysis of the social construction of eHealth. The final goal is to also provide relevant information for policy making in rural contexts in terms of the development of eHealth projects. Bringing an international comparative perspective, the three countries participating in the research provide a diverse landscape in terms of digitalisation of eHealth services, population density, ageing, and cultural norms and beliefs. By studying rural eHealth with a socio-cultural approach and in a comparative perspective, it is possible to go beyond a mere technological perspective and to understand how cultural capital, care ideology and territorial context are related to different uses, needs, competences, enthusiasm and fears about digital care for older adults, and how that differs in different national settings.

\section{Contextual information: demographic profiles, health systems and eHealth use}

Before presenting the results of our comparative analysis, we offer some useful background information to help understand the different national contexts in which the analysed policy documents were written. In the presentation of the characteristics of the three countries, we will focus in particular on the following three aspects: the demographic profile (in particular the number of older people and their health condition), the health system, and the level of digitisation and eHealth use.

The three countries in our sample are all characterised by substantial populations of citizens over 65 years and by rapid ageing processes (Table 1).

There are profound differences in 'how' one gets older. To understand the similarities and differences between the three countries, we use the active ageing index (AAI), which is a synthetic index that describes the ageing processes starting from the weighting of different indicators of the state of wellbeing of older adults. An elaboration of the AAI produced by the United Nations Economic Commission for Europe (2019) divides the European countries into four clusters according to the scores achieved in the different indicators of the AAI. Italy belongs to the cluster of Mediterranean countries that score low in the four domains of the AAI (Employment; Participation in society; Independent, healthy and secure living; and Capacity and enabling environment for active ageing). Sweden and Finland belong to the cluster of the Nordic countries and present well above average results 
Table 1. Demographic profile

\begin{tabular}{|c|c|c|c|c|c|c|}
\hline & \multicolumn{2}{|c|}{$\begin{array}{l}\text { Percentage aged } 65 \\
\text { years or over }\end{array}$} & \multicolumn{2}{|c|}{$\begin{array}{l}\text { Life expectancy } \\
\text { (years) }\end{array}$} & \multicolumn{2}{|c|}{$\begin{array}{c}\text { Old-age } \\
\text { dependency ratio } \\
(65+\text { years } / 20-64 \\
\text { years })\end{array}$} \\
\hline & 2019 & 2050 & Male & Female & 2019 & 2050 \\
\hline Italy & 23.0 & 36.0 & 79.9 & 84.7 & 39.0 & 74.4 \\
\hline Finland & 22.1 & 27.6 & 77.7 & 83.7 & 39.2 & 51.4 \\
\hline Sweden & 20.2 & 24.6 & 80.0 & 83.8 & 35.5 & 45.5 \\
\hline
\end{tabular}

Source: United Nations (2020).

in three domains, and only slightly higher values in the domain of Independent, healthy and secure living (Table 2). Some notable differences between Sweden and Finland are that life expectancy is a bit higher in Sweden, particularly among men, and that expenditures on social services are higher in Sweden, while older adults in Finland use eHealth more than their Swedish counterparts.

The three countries in our sample have free of cost or low cost, universal and decentralised health systems. Overall, the Italian health system is considered efficient (Organisation for Economic Co-operation and Development (OECD), 2019) and ensures good access to high-quality health-care services at relatively low costs, although there are considerable differences between the regions in the country. The main challenges for the Italian health system are to improve the co-ordination of health-care services for the growing segment of the population affected by chronic diseases and to reduce disparities in access to treatment. In 2017, health-care expenditure per capita in Italy was 15 per cent lower than the EU average. About 75 per cent of health-care expenditures are financed with public funds, while the remainder is mainly paid by patients. The National Health Service is decentralised and organised on a regional basis. The central government puts part of the general tax revenues into the health-care services financed with public funds, defines the package of health services (the so-called Essential Levels of Assistance) and performs a general management role. Each region is responsible for the organisation and delivery of health services through accredited public and private hospitals.

According to the OECD (2019), the Finnish health system is complex and decentralised, and is governed at the national and local levels. At the national level, the Ministry of Social Affairs and Health is responsible for health policies with the support of a network of experts and consultative bodies. Local authorities (over 300 municipalities) play a key role in the provision of health services, and they finance and organise primary care and hospital care. In the past 15 years, the Finnish political system has attempted to implement health and social care reforms. The proposed reforms aim at greater centralisation of resources and responsibilities at the regional level with the aim of improving equality of access to care and controlling costs: 'While high levels of decentralisation allow the health system to adapt to the needs of a dispersed population, it generates some inequalities and inefficiencies' (OECD, 2019). Per capita health-care expenditure in Finland has increased in 
Table 2. Active ageing index indicators

\begin{tabular}{|c|c|c|c|c|c|}
\hline & Employment $^{1}$ & $\begin{array}{l}\text { Participation } \\
\text { in society }\end{array}$ & $\begin{array}{l}\text { Independent, } \\
\text { healthy and } \\
\text { secure living }\end{array}$ & $\begin{array}{l}\text { Capacity and } \\
\text { enabling } \\
\text { environment } \\
\text { for active } \\
\text { ageing }^{4}\end{array}$ & $\begin{array}{c}\text { Overall } \\
\text { score }\end{array}$ \\
\hline Italy & 28.0 & 17.3 & 69.9 & 55.9 & 34.0 \\
\hline Sweden & 45.4 & 26 & 76.9 & 71.2 & 46.9 \\
\hline Finland & 35.7 & 22.6 & 75.7 & 63.1 & 40.6 \\
\hline EU average & 31.1 & 17.9 & 71.8 & 57.5 & 35.8 \\
\hline
\end{tabular}

Notes: 1 . Indicators: employment rate among 55-74 year olds. 2. Indicators: voluntary activities; care to children and grandchildren; care to infirm and disabled people; political participation. 3. Indicators: physical exercise; access to health services; independent living; financial security; physical safety; lifelong learning. 4. Indicators: remaining life expectancy at age 55; share of healthy life expectancy at age 55; mental wellbeing; use of information and communication technologies; social connectedness; educational attainment. EU: European Union.

Source: United Nations Economic Commission for Europe (2019).

the past 10 years and is slightly above the EU average. Public funding covers 75 per cent of all health-care expenditure, which is somewhat lower than the EU average (79\%). The patients pay most of the remaining expenses.

The Swedish health service system is decentralised and provides universal coverage. Sweden has the third-highest health expenditure in the EU as a percentage of Gross Domestic Product and the third-highest per capita expenditure. Most of the health-care expenditure is financed with public funds (84\%), which is somewhat higher than the EU average (79\%). The national government is responsible for regulation and oversight, while the regions are responsible for funding, purchasing and providing health services. Regions are responsible for primary and specialist care, while municipalities are responsible for care for elderly people, care for people with physical and mental disabilities, rehabilitation services, school health care, home care and social assistance. Health-care costs are mainly paid through local taxes, along with contributions from the national government. Over the last decades, the Swedish health-care system has gone through a significant marketisation, with increased numbers of private care actors envisioned to increase efficiency and quality of care (Blomqvist, 2004; Stolt and Winblad, 2009, Stolt et al., 2011; Andersson and Kvist, 2015).

The three countries in our sample are characterised by profound differences in terms of the diffusion and use of information and communication technologies (ICT). In particular, Italy differs from the Nordic countries in terms of a generally lower level of innovation. However, in terms of the spread of broadband connections, the three countries do not have big differences, and 94.8 per cent of households in Sweden, 93.1 per cent of households in Finland and 83.7 per cent of households in Italy are reached by a fast internet connection (Eurostat, 2019). When comparing the use of the internet, however, the gap begins to grow. The proportion of individuals between 16 and 74 years old who regularly use the internet (at least once a week) are 95.4 per cent in Sweden, 93.4 per cent in Finland and 73.9 per cent in Italy (Eurostat, 2019). In terms of digital skills, the gaps between the 
Nordic countries and Italy become significant, and the proportions of individuals with above basic levels of digital skills are 50.1 per cent in Finland and 46 per cent in Sweden, but only 22 per cent in Italy (Eurostat, 2019). The gaps become even deeper if the analysis focuses on different age groups, and while internet use is more equally distributed in the populations of Sweden and Finland, Italy suffers from a dramatic age-related divide. Swedish and Finnish citizens between 65 and 74 years of age are regular internet users, at 80.5 and 74.7 per cent, respectively, compared to 39.2 per cent of Italians of the same age. A further element that differentiates Italy from Sweden and Finland is the use of eGovernment services, i.e. the use of technological communication devices to provide social services to citizens. In this case, the gap between Italy and the Nordic countries is even more marked. In the past 12 months, only 23.4 per cent of Italians have used an eGovernment service compared to 87.3 per cent of Finns and 86 per cent of Swedes (Eurostat, 2019).

Going deeper into the issue of digital services for eHealth, the differences between Italy and the Nordic countries are also significant. These data are to be contextualised both in terms of lack of eHealth services and in the low digitisation of users, primarily users over 65 , including both patients and doctors, and 49 per cent of people in Finland, 33 per cent of people in Sweden and 24 per cent of people in Italy have used online health and care services without physically going to a health-care facility (e.g. by getting a prescription or a consultation online) (Eurostat, 2018, 2019). The gaps between Italy, Sweden and Finland get deeper when looking at the digitisation of general practitioners and the digitisation of the health-care system in general (Figure 1).

\section{Methodology}

\section{Sample}

Our data consist of national and regional policy documents for promoting eHealth among older adults in Italy, Finland and Sweden. Our sample comprises the most relevant national and regional policy documents about eHealth, ageing, rurality and fragility published between 2009 and 2019.

The Italian sample includes 59 documents, including four documents from national government agencies, one from the Ministry of Innovation, one from the Ministry of Economic Development, seven from the Ministry of Health and 46 from regional administrations. The Finnish sample includes 21 documents, including four laws, two government programmes and four documents from government agencies, six from the Ministry of Health and Social Affairs, two from the Ministry of Finance, one from the Ministry of Transport and Communications and two from the County of Lapland. The Swedish sample includes 15 documents, including 13 Swedish government official reports and two written communications from the government (see the online supplementary material).

\section{Analysis}

Starting from the conceptual discussion on the digital landscape of care and using a grounded theory approach (see Strauss and Corbin, 1994), our qualitative content analysis (see Hsieh and Shannon, 2005) involved three steps: (a) mapping and 


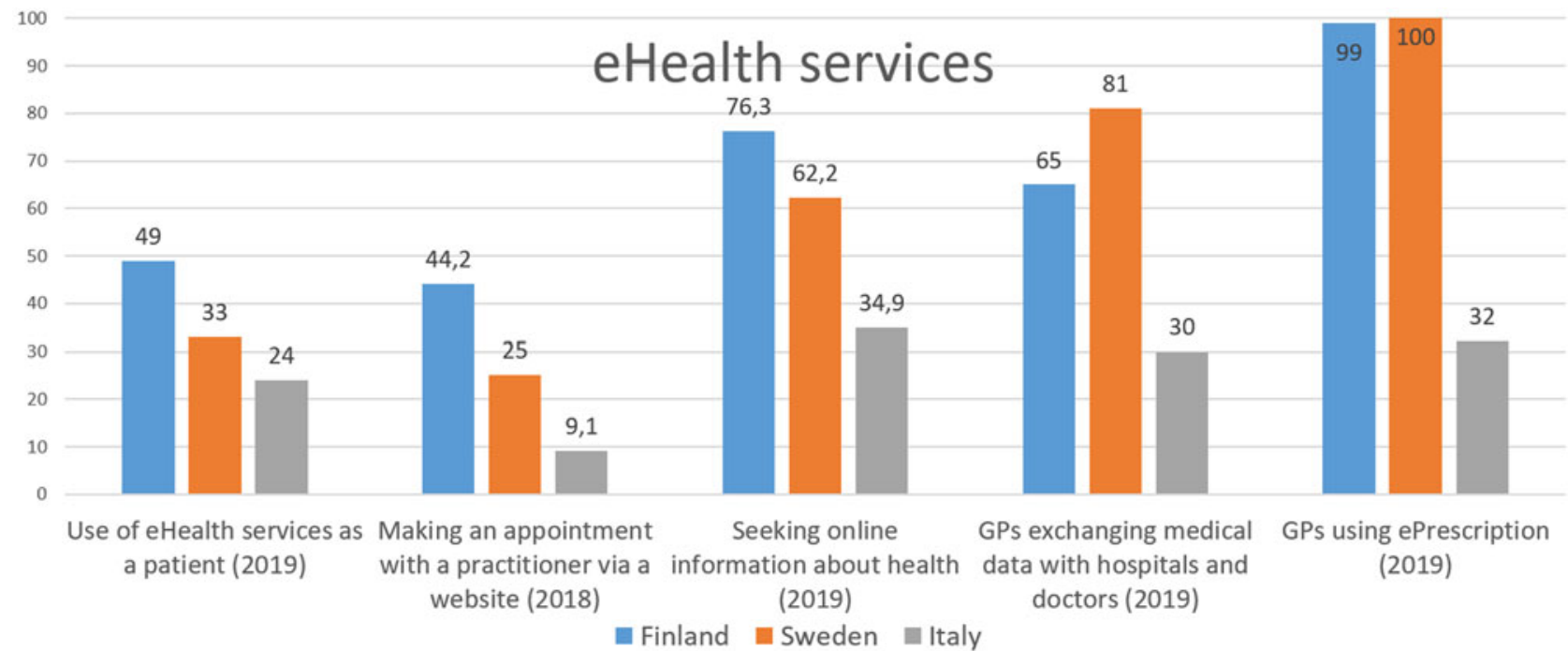

Figure 1. Use of eHealth services (percentage of individuals; percentage of general practitioners (GPs)). Source: Eurostat $(2018,2019)$. 
selecting national and regional policy documents for promoting eHealth among older adults from 2009 to 2019 in the three countries; (b) identifying broad areas of themes and creating a common list of key concepts ('older people', 'ageing', 'active ageing', 'health', 'eHealth', 'the rural/remote', 'care responsibilities', 'technologies', 'ICTs'); and (c) applying a non-automated content analysis (Elkins et al., 2019) to map whether/how these key concepts were defined in each document in the sample. At the end of the analysis process, we identified three macro-topics on which to articulate the comparison in the framework of a digital landscape of care, namely the role of eHealth technologies, the role of the rural dimension and the constituted care responsibilities that we discuss further in the following sections.

\section{Results}

\section{The role of eHealth technologies}

The documents we analysed highlight the positive role of technology in promoting more efficient health care and elder-care, but there are also some critical and problematic issues raised:

The use of technological innovations in patient management is an opportunity to improve the efficiency and sustainability of continuity of care. (Progetto per la Salute. Piano Sanitario Regionale [Health Project. Regional Health Plan], 2019: 305 , Italy)

Reducing or curbing health-care costs is a cross-cutting priority in the three countries. In particular, it is underlined that, with the ageing population, elder-care will become one of the largest social service costs. It is, therefore, no surprise to note that in many of the analysed documents the role of eHealth is connected to economic efficiency (Sanyal et al., 2018). The development of digital services allows both the reduction of costs related to the management and communication of information between hospitals, doctors and patients (e.g. the reservation systems for visits) and the reduction of costs of care through self-care, self-service, self-help and self-monitoring.

In this sense, the technologies of communication and health save resources that are otherwise destined, on the one hand, to the development of 'physical' structures for the management of health information (offices, counters, telephones, employees) and, on the other, to the provision of medical assistance. In fact, if patients, through technologies, can self-monitor their state of health at home, such monitoring does not have to be done by a doctor in an expensive care facility.

The use of technological innovations in patient management is seen as an opportunity to improve the efficiency and sustainability of 'continuity of care' by being able to treat a patient for longer at home instead of in the hospital, thus reducing the costs of hospitalisation. Finally, eHealth is included in the broader opportunities represented by the health industry (technologies, pharmaceuticals, digital services, biotechnologies), and eHealth could be part of the economic strategy of a country. In particular, some Italian documents underline how, in terms of employment and the volumes of turnover produced, the health industry represents a strategic sector for the economic development of the country. 
According to the documents analysed, a primary target of health technologies is and will be older people. This is true for reasons of efficiency and efficacy. In terms of efficiency, older citizens are the largest target of the national health systems and therefore are necessarily the ones who are targeted in efforts to achieve significant savings in public expenditures. In terms of efficacy, older people are more likely to have chronic diseases, and health technologies are particularly effective in the care of the chronically ill and those in need of continuous assistance. In particular, technology supports older people's independent living and helps avoid hospital stays for chronically ill people. One way to increase ageing citizens' utilisation of new technologies is suggested to be to engage them in the design and testing of health-care technologies.

Not all of the analysed texts speak equally of the possible limits and risks associated with the implementation and use of eHealth. In general, the approach to technology is positive, optimistic and deterministic, and not all documents leave room for the possible negative implications of the use of health technologies or for possible limitations in general.

In particular, in the Italian documents the limitations and risks for end users are not emphasised, and most of the documents discuss the advantages (efficiency and efficacy) of eHealth for the health system and less space is given to the implementation of eHealth for end users. In the Finnish and Swedish documents, limitations and possible risks associated with the development of eHealth services aiming towards older users are more articulated, including issues related to integrity, trust, limited economic resources among older people, and digital competence and confidence. Ethical concerns are addressed in some Finnish and Swedish policy texts, and eHealth and welfare technology is advised to be used with caution and ethical issues kept in mind:

Confidence in digital services is enhanced by engaging in an active social debate on data protection, digital exclusion, self-determination and ethics. (Eheä yhteiskunta ja kestävä hyvinvointi. Sosiaali- ja terveysministeriön tulevaisuuskatsaus [An intact society and sustainable welfare. Ministry of Social Affairs and Health future report], 2018, pp.16-17, Finland)

In its report on ethical aspects of robots and surveillance in the care of the elderly, the Swedish Medical and Ethical Council (SMER) has recommended that an assessment of the consequences the monitoring can have for ethical values must be made before monitoring measures are taken in the care of the elderly. In particular, the Council stresses that it is important that a balance is achieved between the benefits of monitoring and the intrusion on the privacy of the individual that the monitoring entails. The measure should be taken in such a way as to minimise the intrusion. If welfare technology is used, it should be for the good of the older person, and careful analysis and considerations are required about it can violate the older adults' right to privacy and dignity. (Så stärker vi den personliga integriteten [How to strengthen personal integrity], 2017: 126, Sweden)

Other ethical issues in eHealth and elderly users are related to the potential replacing of offline service and more generally the ethical limits of a 'digital-first' 
approach, and digital services risk being perceived as services that 'replace' the opportunities for offline and personal face-to-face contact.

According to previous research, welfare technology has the potential to increase safety and security, give greater independence, and facilitate participation and social contacts, and thus the value of virtual contact should not be underestimated (Bradford et al., 2018). Despite the many proclamations on the centrality of eHealth, the analysed documents offer few elements to understand what the policies should include for improving the use of health technologies among citizens. The Italian documents in particular emphasise public strategies to support private demand and the purchase of eHealth services, but there is no reflection on the accessibility or costs to purchase technologies. The only generic reference to policy that stimulates the use of technologies is the general need to connect and digitise areas of the country that currently have connection difficulties or that do not have access to the internet. In particular, the Italian documents that include eHealth within the reflection on the country's innovation and digitalisation (e.g. the local implementation of the European Digital Agenda 2020) indicate the increase in the spread of broadband and the adoption of digital technologies as a prerequisite for the development of eHealth policies. In the Swedish and Finnish documents, there are attempts to describe more specific policies and actions that would favour the use of eHealth services, but only a few generic examples are given, such as a tax reduction for information technology services in the home or through encouraging the use of online services through a reduction of traditional channels of access to health care.

\section{The rural issue}

In Finland and Sweden, the most rural areas are in the northern parts of the country, while in Italy the mountains are the most remote areas. In rural areas in each country, the population density is lower than in other parts of the country, and there are long distances and travel times from sparsely populated residential areas to municipal centres and services. In addition, sparsely populated areas are ageing more rapidly than other parts of the countries and care needs are higher. eHealth is considered to be one solution to overcoming the distance gap in all three countries. However, ageing and declining rural areas are contradictory to the optimistic expectations on ICT and eHealth.

In all three countries, the idea of equality and equal services for all people, despite where they live, is emphasised highly:

All regions should be able to offer the same service and equal care to all citizens, but it cannot be expected to be designed in the same way everywhere, depending on, for example, changing conditions in sparsely populated and large cities. (God och nära vård [Good and close care], 2017: 69, Sweden)

In the documents, eHealth is seen as a tool to promote equity of access to health care for all citizens, even in more remote areas. However, in the policy documents it is stated that the population cannot expect all health and social services to be performed in the same way, particularly in sparsely populated areas. In the Swedish policy text the concept of 'close care services' is introduced as a redefinition of 
what might count as a care encounter, enabling even sparsely populated areas to offer equal care and social services to all citizens. Traditionally, a care encounter has been understood as a physical meeting between the patient and the care professionals in a care facility, and with eHealth solutions more of the everyday care can be done digitally from the home. The technological solutions are seen as an answer to guarantee that everyone in the population has an opportunity to have their care needs met - citizens have the opportunity to communicate electronically with service providers regardless of their place of residence, and electronic solutions ensure equal access to services in sparsely populated areas. Universal access to care means offering the same standard of care to patients living in cities or in isolated communities:

The current rather one-sided focus on the traditional mediation logic 'physical meeting in health care' must be shifted to include other forms of interaction with the patient. The patient's needs and opportunities need to be better met by health care. The technical possibilities are great today to meet needs without physical meetings, but the technology needs to be spread so that everyone in the population has the opportunity to have their care needs met in this way. (Effektiv vård [Efficient care], 2016: 363, Sweden)

As local services are being closed due to austerity policies, there is an increased risk of inequalities in access to adequate health care, particularly in areas with large ageing populations. The analysed policy documents suggest that digitalisation creates opportunities for primary care to develop services that create greater accessibility for patients, enable remote monitoring and monitoring in the home, and streamline work methods and processes for sharing information between care-givers. To some extent, geographical distance is suggested to be compensated for through technical solutions.

There are regional differences and regional diversification in service supply, and municipalities and regions have different starting points and resources to guarantee services. Inequality and segregation of residential areas involve security risks, and rural areas are widely seen as a place for the diffusion of digital solutions. In addition, different areas have their own strengths, which can be emphasised by strengthening regional and local decision-making and co-operation. eHealth is one solution to strengthening rural areas with a strong dispersion of population density. The virtual communications network between citizens and primary care services can use ICT in many ways, and the eHealth services should mainly be provided in areas defined as 'internal or rural areas' that are disadvantaged from a geographic point of view.

Rural areas are often not very interesting for private and commercial service producers. The size of the municipality affects the number of ICT solutions that are available and the number of ICT-skilled professionals, including both health-care providers and ICT support personnel, and thus these areas need public intervention for the diffusion of technologies. Rural hospitals and service centres can use broadband to provide care and medical skills identical to those available in units in urban centres. According to the policy documents, eHealth services can offer new opportunities for public service in sparsely populated areas because the service can be provided without the patient having to travel to obtain care. However, remote 
areas can, from the viewpoint of care services, be challenging. In Italy, for example, a specific mortality and morbidity gap still characterises populations in mountainous areas, especially for tumours and cardio-cerebrovascular diseases. Sparsely populated and remote areas in general face obstacles of low diffusion of ICT, digital divide, interoperability, lack of ICT devices, and lack of digital skills among older adults and health and social care workers.

\section{Care responsibilities}

In all three countries, the responsibility to guarantee the supply of needed care is on public actors, be they at the state or regional level. In Finland and Sweden, the right to needed care and services is written into the constitution and elder-care legislation:

The obligation of the municipality is to take care of the wellbeing, health and functional capacity and independent performance of its elderly population and to ensure the social and health services needed by the elderly (2§). (Laki ikääntyneen väestön toimintakyvyn tukemisesta sekä iäkkäiden sosiaali- ja terveyspalveluista [Act on Supporting the Functional Capacity of the Older Population and on Social and Health Services for Older Persons] (980/2012), Finland)

Municipalities are responsible for providing care and services according to the needs of their inhabitants. In guideline documents, it is stated that citizens should be supported in taking responsibility for their own wellbeing, meaning that both society and the individual must take equal responsibility. In Italy, the regions are by law responsible for health care and social services, and the regions have broad autonomy in defining health guidelines. Regional health systems have unequal performance and, being partially funded by local taxation, the wealthier regions have more developed health systems.

In all three countries, de-hospitalisation and ageing in place are emphasised. The grounds for this development are twofold. On the one hand, care and services are increasingly being delivered at home in order to reduce health and social care costs and to increase user comfort. On the other hand, older adults themselves wish to stay in their own home for as long as possible. For example, Italy is moving from a model that includes a small hospital in every medium-sized city to the de-hospitalisation and transformation of hospitals into local health-care centres and the transformation of private homes into 'nursing homes'. eHealth technologies are used to assist with the provision of care and services in homes and to allow remote online consultations with health specialists, and eHealth services are used as tools to guarantee communication between and continuity of care between specialists and primary care.

In Finland and Sweden, supporting family carers via home help services and combining work and family life are widely supported in the analysed documents. Despite the legislations' emphasis on the responsibility of the municipalities, the actual responsibility of family members is strongly interwoven into the care of older adults with care needs (Zechner and Valokivi, 2012). Families carry out most of the care responsibilities (Ulmanen and Szebehely, 2015), and there is reason to assume that 
the relatives of older people with great care needs must put significant efforts into organising and delivering their care. This is a major responsibility for these relatives:

Care responsibility can affect not only the physical and mental health of the relatives, but can also affect their opportunities to work, engage in leisure activities and recreation, and to maintain other important relationships. (Effektiv vård [Efficient care], 2016: 449, Sweden)

The versatility of service providers in the field will be taken into account, and different forms of care services, including family care and other intermediate solutions, will be further developed. (Pääministeri Sanna Marinin hallituksen ohjelma 2019 [Prime Minister Marin's Government Programme 2019], 2019: 159, Finland)

Studies on care show that co-ordination often fails for family carers, and they have few opportunities to be involved in the co-ordination of the care, and in many cases poor co-ordination leads to poorer care as well as an uncertain situation for the person in need of care. In addition, the relatives are often forced to take responsibility for the co-ordination of care (Szebehely et al., 2014). At the same time, it is more common among women than among men that caring leads to negative consequences in terms of the ability to uphold gainful employment and in terms of physical and mental health. Family care is also more common in lower-income groups (Ulmanen and Szebehely, 2015). There is no evidence to suggest that the proportion of care-givers is greater in northern Europe than southern Europe, although the scope of social care is narrower in southern Europe. In the Nordic countries and in the Netherlands, with extensive public funding, it is less common for families to provide intensive and time-consuming care efforts to their ageing relatives (Szebehely, 2014).

In the documents, self-responsibility is emphasised:

[Territorial health services] must promote patient self-care and users' awareness of their personal resources by trying to offer alternative visions to those of 'dependency'. (Strategie aree interne Lazio [Internal areas strategies Lazio], 2019: 284, Italy)

The fact that the public administration is responsible for ensuring basic rights does not negate the responsibility of the individual for his/her choices (Sosiaalisesti kestävä Suomi 2020. Sosiaali- ja terveyspolitiikan strategia [Socially sustainable Finland 2020. Social and health policy strategy], 2011: 10, Finland)

The patient's ability to actively participate in and manage his own care needs to be strengthened. (Effektiv vård [Efficient care], 2016: 380, Sweden)

Self-care and digital self-care are seen as future solutions for meeting increasing care needs, but self-care and digital self-care cannot succeed without help from informal networks. Peer and family support are called for in the documents, and this call increases the digital care responsibilities of the informal network. However, if 
older persons do not receive this ICT support from informal carers, or they do not have family or support networks, they will be in an unequal position:

Peer support is a way of providing digital support by a number of organisations, especially older people's organisations ... One major informal form of support for digital devices and services is support from friends and relatives. (Digituen toimintamalliehdotus. AUTA-hankkeen projektiryhmän loppuraportti. Valtiovarainministeriö [Ministry of Finance, Digital support policy proposal. Final Report of the AUTA Project Team], 2017: 17, 21, Finland)

eHealth is seen to open possibilities of digitalisation and new opportunities for rapid information transfer and opportunities to develop support systems for the health-care professions. Digitalisation also gives patients and their relatives new opportunities to become involved in care and brings the professionals and patients closer together. From an ethical perspective, the most important questions are how welfare technology can contribute to the ability of older people to be independent and can facilitate communication with relatives as well as with health-care staff and how such technology can increase older people's safety, health and wellbeing.

In Italy there is a growing role of pharmacies as principals not only for medical advice, but also as a place for the management of digital health activities. Pharmacies, given their widespread diffusion in urban and rural centres, are points of reference in the case of emergencies in the area and are a 'technological' node for the provision of services such as booking networks for visits to hospitals and surgery, downloading medical reports, receiving electronic prescriptions and managing the patient's electronic health record. Faced with the contraction in medical supplies and the number of general practitioners, pharmacies have become essential nodes of the 'Territorial Health Information System' developed by the regions:

The social function for health protection that rural pharmacies in particular perform in disadvantaged areas in order to protect the population and in particular the elderly, also assumes particular importance. (Progetto per la Salute. Piano Sanitario Regionale [Health Project. Regional Health Plan], 2019: 305, Italy)

Another example of extended care networks in Italy is the 'family and community nurse' who contributes to helping older inhabitants in the area live independently at home for as long as possible. A 'community nurse' model of taking charge of and supporting the older population functions as a connection between the older person, their family network, and the various professionals and eHealth services (general practitioners, specialists, hospitals and pharmacies, as well as governing bodies, associations and private individuals) in order to promote inclusion, health, and psychological and physical wellbeing.

The introduction of technology in older person's care involves new actors and professionals in the already-complex networks of care surrounding ageing adults. For example, children or grandchildren who are more familiar with technologies are asked to help more often, and formal care-givers sometimes assume their help. In addition, technology advisers might be new professionals in older persons' 
care networks (Outila and Kiuru, 2021). These changes might challenge the nature of family relationships as well as the quality of care, something that must be kept in mind. A Swedish study also showed how children and grandchildren are

strongly involved in nearly every stage of technology domestication, from appropriation (i.e. identifying the need, buying the item, and installing and adjusting it) to incorporation (i.e. choosing and downloading suitable apps, teaching how to use them, and solving technical problems). (Olsson and Viscovi, 2018: 324)

Olsson and Viscovi (2018) point out that even though elderly Swedes have been accustomed to online activities for more than a decade, the need for continuous assistance seems to prevail also among experienced users.

\section{Comments and concluding remarks: the landscape of eHealth care in policy documents}

To understand the differences and similarities found in the three studied countries' eHealth policy processes, we use the notion of digital landscape of care. The care of older adults is complex, relationally as well as spatially, bodily and organisationally (Milligan and Wiles, 2010; Lindberg and Carlsson, 2018). In understanding these complex relations, it is important to take into consideration socio-structural processes and structures, experiences and practices of care, as well as support, services, ethics, morals, responsibilities and the spatial politics of care. In Lindberg and Carlsson's (2018) analysis of eHealth and digital landscapes of care, they concluded that eHealth is often welcomed with optimism and that it is believed to improve the quality of care, reduce the costs of care and activate older adults in taking care of themselves, but they also concluded that these discourses need to be critically analysed. We found similar discourses in this study. All studied countries formulated eHealth as a mainly positive development, with an emphasis on increased economic efficiency and cost reduction in health care. eHealth is thus seen, in line with the general interpretation of digitalisation, as a tool capable of doing the same things as face-to-face services but at lower costs (see Sanyal et al., 2018).

In all three countries, increased digitalisation is seen not only as an opportunity, but also as a necessity to meet the increased austerity in the health-care system. It is also argued that eHealth will provide opportunities for a new care model that will increase user involvement and accessibility in health care. This care model is thought to be particularly beneficial for ageing populations, the chronically ill and those living in rural areas. eHealth is expected to facilitate older adults to remain in their homes longer, to avoid unnecessary and prolonged hospital stays, to increase safety and security, to reduce loneliness and social isolation, to provide opportunities to intervene against anticipated and preventable health deterioration, to assist in physical rehabilitation and medicine distribution, and to encourage physical activity. However, in the policy texts in all three countries it is pointed out that the digital competence and economic means, as well as mental and physical abilities, vary greatly among older adults. This is something that needs to be taken into consideration in relation to eHealth.

Digitalisation of health care can offer the opportunity to connect with the highest quality health services even if one lives far away from them or if one is unable to 
leave one's home. However, we find this eHealth discourse problematic because it mainly points to individual factors, such as individual competence or means, in relation to the digitalisation of elder-care. A greater reliance on digitalisation in elder-care and health care demands that the problems in digital infrastructures be addressed properly. Digital accessibility needs to be considered as a social right, particularly in rural areas, not just as an issue for the individual to take up or the market to take care of. There are some initiatives in the policy processes, such as tax rebates on ICT services and redefining the role of pharmacies, but especially from the rural perspective these are not enough.

These problematic questions could be found in all three studied countries. However, as could be expected due to the profound differences between the three countries, particularly between Italy and the Nordic countries, with respect to welfare organisation, territorial structuring and digitalisation among government agencies and citizens, there were also differences in the countries' approaches to eHealth. One such example is that in the Italian documents there was hardly any problematisation of the impact of technological transformations in the health system, in the lives of older adults, or in the relationship with the health system and health-care professionals, while such discourses were emphasised in the Finnish and Swedish documents. In the Nordic documents, there was a reflection on both ethical issues and risks, such as technological dysfunctions on both the user and system levels (see also Pirhonen et al., 2020). The Italian documents seem less nuanced from this perspective. Instead, they accent the need for an optimistic push due to the lack of digitisation in remote areas of the country and the ageing sections of the population. The Italian policy is characterised by a techno-positive approach that mainly emphasises the positive sides of increased digitalisation, and it argues for the benefits for society, the health-care system and citizens, and in line with this there is an absence of problematic or more complex issues regarding eHealth. In the Nordic texts there are, for instance, discussions about user involvement, including both of ageing citizens and health-care professionals, in the early stages of the design processes of digitalisation, something that is only marginally described in the Italian texts.

Another major critical observation is the lack of consideration of the impact of increased digitalisation of health care on the care networks that surround older adults. Informal carers, family members and friends also need to be taken into consideration in the implementation of eHealth and the digitalisation of the care of older adults. When greater emphasis is put on the individual's responsibility for their own health care, a heavier care burden might land on the shoulders of significant others and informal carers. The cost reduction for the health-care systems might be made up for through rising care responsibilities for the families and informal care networks, along with increased inequalities in accessing elder-care (Szebehely, 2014). This is a development that risks becoming even more problematic when such care networks of family and friends are missing or insufficient.

In light of our study, eHealth as a digital landscape of care needs to be evaluated from the perspective of the construction of a 'proper' care receiver and 'reasonable' care, as well as the power structures and rationales that lie behind these constructions. Studies (e.g. Schou and Hjelholt, 2019; Sundberg, 2019) have pointed out how digitalisation is made to seem inevitable and how a 'digital citizen' (Schou and 
Hjelholt, 2019) is constructed to promote the legitimisation of digitalisation. Similarly to our study, Schou and Hjelholt (2019) see digitalisation as being strongly connected to economically sound-looking politics in the sense of efficiency and flexibility. The construction of a 'digital citizen' also includes the idea of responsibilisation (see Juhila et al., 2017). In contrast to the inevitable nature of digitalisation, the making of a 'digital citizen' should be understood as a political figuration (Schou and Hjelholt, 2019).

Sundberg (2019) calls attention to how many eGovernment policies contain myths and visionary images about technology. According to Sundberg, current discourses on digitalisation represent views where technology dictates the conditions that lead us towards an inevitable technology-driven future. For example, issues such as digital divides are left in silence because the proposed solution to the problems presented in the policy is that everyone should embrace the technology. From the perspective of the digital landscape of care, the care of older adults is a complex and relationally as well as spatially, bodily and organisationally driven phenomenon, and it needs to be analysed thoroughly. Digitalisation of elder-care and eHealth needs to take into consideration the complexities that surround each older adult with care needs by asking questions about where they live, how they live and who is caring for them, and by addressing issues regarding the functionality and support of digital devices and the practicality of the digital infrastructure. Policy makers need to be less concerned with convincing reluctant older adults, their close relatives and grassroots-level professionals of the benefits of the eHealth and be more concerned about providing functional digital infrastructure and diminishing inequalities that exist in the field. Issues related to exclusion that should be addressed here are the first-level digital divide including physical and material access, the second-level digital divide including user skills and usage (van Deursen and Van Dijk, 2019), and the third-level digital divide including tangible outcomes of use, e.g. the use either resulting in benefits or not (van Deursen and Helsper, 2015).

As we write this, we are in the middle of the COVID-19 pandemic crisis, which has affected us all but with particularly devastating and lethal consequences for the elderly and most vulnerable citizens. During the crisis, social distancing has become one main advised strategy, especially for older persons, and the pandemic has in some ways become a devastating stress test for digital solutions for health and care and shows how increased digitalisation in health care can contribute to preventing contagious diseases. Because we have studied policy documents on eHealth from the last 10 years in Italy, Finland and Sweden, we can conclude that this major societal challenge was not foreseen by these governments and policy institutions. Until now, the development of eHealth has been thought of as a slow digital transition process and not as a tool to offer care in the context of unexpected widespread 'domestic isolation'. From this point of view, the COVID-19 pandemic will probably represent a fundamental watershed both for eHealth policies and for a general rethinking of new (digital) models of care.

Supplementary material. The supplementary material for this article can be found at https://doi.org/10. 1017/S0144686X21000945

Author contributions. All authors contributed equally to the text. 
Financial support. This work was supported by the HARVEST Project which received funds under the JTC 2017 launched by Joint Programming Initiative (JPI) MYBL. JPI MYBL is supported by J-Age II. J-Age II is funded by Horizon2020, the EU Framework Program for Research and Innovation (grant agreement number 643850, 'More Years, Better Lives').

Conflict of interest. The authors declare no conflicts of interest.

Ethical standards. No ethical approval was needed (open-source policy data).

\section{References}

Airola E, Rasi P and Airola M (2020) Older people as users and non-users of a video conferencing service for promoting social connectedness and well-being - a case study from Finnish Lapland. Educational Gerontology 46, 258-269.

Andersson K and Kvist E (2015) The neoliberal turn and the marketization of care: the transformation of eldercare in Sweden. European Journal of Women's Studies 22, 274-287.

Anttonen A and Sipilä J (1996) European social care services: is it possible to identify models? Journal of European Social Policy 6, 87-100.

Antunes TPC, Oliveira ASB, Hudec R, Crocetta TB, Ferreira de Lima Antao JY, de Almeida Barbosa RT, Guarnieri R, Massetti T, Garner DM and de Abreu LC (2019) Assistive technology for communication of older adults: a systematic review. Aging \& Mental Health 23, 417-427.

Barbosa Neves B, Franz R, Judges R, Beermann C and Baecker R (2017) Can digital technology enhance social connectedness among older adults? A feasibility study. Journal of Applied Gerontology 38, 49-72.

Bentley CL, Powell LA, Orrell A and Mountain GA (2018) Making telecare desirable rather than a last resort. Ageing \& Society 38, 926-953.

Bettio F and Plantenga J (2004) Comparing care regimes in Europe. Feminist Economics 10, 85-113.

Blomqvist P (2004) The choice revolution: privatization of Swedish welfare services in the 1990s. Social Policy \& Administration 38, 139-155.

Bond CS and Worswick L (2015) Self management and telehealth: lessons learnt from the evaluation of a Dorset telehealth program. The Patient 8, 311-316.

Bradford DK, Van Kasteren Y, Zhang Q and Karunanithi M (2018) Watching over me: positive, negative and neutral perceptions of in-home monitoring held by independent-living older residents in an Australian pilot study. Ageing \& Society 38, 1377-1398.

Brown AD, Colville I and Pye A (2015) Making sense of sensemaking in organization studies. Organization Studies 36, 265-277.

Chen YRR and Schulz PJ (2016) The effect of information communication technology interventions on reducing social isolation in the elderly: a systematic review. Journal of Medical Internet Research 18, e18.

Choi NG, Hegel MT, Marti CN, Marinucci ML, Sirrianni L and Bruce ML (2014) Telehealth problem-solving therapy for depressed low-income homebound older adults. American Journal of Geriatric Psychiatry 22, 263-271.

Claes V, Devriendt E, Tournoy J and Milisen K (2015) Attitudes and perceptions of adults of 60 years and older towards in-home monitoring of the activities of daily living with contactless sensors: an explorative study. International Journal of Nursing Studies 52, 134-148.

Cook E, Randhawa G, Sharp C, Ali N, Guppy A, Barton G, Bateman A and Crawford-White J (2016) Exploring the factors that influence the decision to adopt and engage with an integrated assistive telehealth and telecare service in Cambridgeshire, UK: a nested qualitative study of patient 'users' and 'non-users'. BMC Health Services Research 16, 137.

Currie M, Philip LJ and Roberts A (2015) Attitudes towards the use and acceptance of eHealth technologies: a case study of older adults living with chronic pain and implications for rural healthcare. $B M C$ Health Services Research 15, 162.

Daly ME (ed.) (2001) Care Work: The Quest for Security. Geneva: International Labour Organization.

Delello JA and McWhorter RR (2017) Reducing the digital divide: connecting older adults to iPad technology. Journal of Applied Gerontology 36, 3-28.

Elkins Z, Spitzer S and Tallberg J (2019) Content Analysis, Non-automated (American Political Science Association Organized Section for Qualitative and Multi-method Research, Qualitative Transparency 
Deliberations, Working Group Final Reports, Report III.5). Available at https://papers.ssrn.com/sol3/ papers.cfm?abstract_id=3333485.

European Commission (2017) The State of Health in the EU: Companion Report 2017. Luxembourg: Publications Office of the European Union.

European Commission (2018) Communication from the Commission to the European Parliament, the Council, the European Economic and Social Committee and the Committee of the Regions on Enabling the Digital Transformation of Health and Care in the Digital Single Market; Empowering Citizens and Building a Healthier Society (COM/2018/233). Available online at https://eur-lex.europa.eu/legalcontent/EN/TXT/?uri=COM\%3A2018\%3A233\%3AFIN.

European Commission and Economic Policy Committee (2016) Joint Report by the Commission Services and the Economic Policy Committee on Health Care and Long-term Care Systems and Fiscal Sustainability, October 2016. Luxembourg: Publications Office of the European Union.

Eurostat (2018) Digital Agenda Scoreboard Key Indicators. Available online at https://digital-agenda-data. eu/datasets/digital_agenda_scoreboard_key_indicators

Eurostat (2019) Digital Agenda Scoreboard Key Indicators. Available online at https://digital-agenda-data. eu/datasets/digital_agenda_scoreboard_key_indicators.

Fischer SH, David D, Crotty BH, Dierks M and Safran C (2014) Acceptance and use of health information technology by community-dwelling elders. International Journal of Medical Informatics 83, 624-635.

Frennert SA, Forsberg A and Östlund B (2013) Elderly people's perceptions of a telehealthcare system: relative advantage, compatibility, complexity and observability. Journal of Technology in Human Services 31, 218-237.

Hasan $\mathbf{H}$ and Linger $\mathbf{H}$ (2016) Enhancing the wellbeing of the elderly: social use of digital technologies in aged care. Educational Gerontology 42, 749-757.

Heart T and Kalderon E (2013) Older adults: are they ready to adopt health-related ICT? International Journal of Medical Informatics 82, 209-231.

Hsieh H-F and Shannon SE (2005) Three approaches to qualitative content analysis. Qualitative Health Research 15, 1277-1288.

Juhila K, Raitakari S and Hansen Löfstrand C (2017) Responsibilisation in governmentality literature. In Juhila K, Raitakari S and Hall C (eds). Responsibilisation at the Margins of Welfare Services. London: Routledge, pp. 11-34.

Kerssens C, Kumar R, Adams AE, Knott CC, Matalenas L, Sanford JA and Rogers WA (2015) Personalized technology to support older adults with and without cognitive impairment living at home. American Journal of Alzheimer's Disease \& Other Dementias 30, 85-97.

Khosravi P and Ghapanchi AH (2016) Investigating the effectiveness of technologies applied to assist seniors: a systematic literature review. International Journal of Medical Informatics 85, 17-26.

Kilpeläinen A and Seppänen M (2014) Information technology and everyday life in ageing rural villages. Journal of Rural Studies 33, 1-8.

Kim K-I, Gollamudi SS and Steinhubl S (2017) Digital technology to enable aging in place. Experimental Gerontology 88, 25-31.

Kvist E (2012) Changing social organizations of care: a comparison of European policy reforms encouraging paid domestic work. European Journal of Ageing 9, 111-117.

Lie ML, Lindsay S and Brittain K (2016) Technology and trust: older people's perspectives of a home monitoring system. Ageing \& Society 36, 1501-1525.

Lindberg J and Carlsson E (2018) Digitala vårdlandskap - kritiska reflektioner om e-hälsa i glesbygden. Socialmedicinsk tidskrift 95, 62-69.

Lister R, Anttonen A, Gerhard U, Bussemaker J and Williams F (2007) Gendering Citizenship in Western Europe: New Challenges for Citizenship Research in a Cross-national Context. Bristol, UK: Policy Press.

Lutz H (ed.) (2016) Migration and Domestic Work: A European Perspective on a Global Theme. Abingdon, UK: Routledge.

Milligan C and Wiles J (2010) Landscapes of care. Progress in Human Geography 34, 736-754.

Mitzner TL, Stuck R, Hartley JQ, Beer JM and Rogers WA (2017) Acceptance of televideo technology by adults aging with a mobility impairment for health and wellness interventions. Journal of Rehabilitation and Assistive Technologies Engineering 4, 1-12. 
Olsson T and Viscovi D (2018) Warm experts for elderly users: who are they and what do they do? Human Technology 14, 324-342.

Organisation for Economic Co-operation and Development (OECD) (2019) Country Health Profiles 2019. Available at https://ec.europa.eu/health/state/country_profiles_en.

Østensen E, Gjevjon ER, Øderud T and Moen A (2017) Introducing technology for thriving in residential long-term care. Journal of Nursing Scholarship 49, 44-53.

Östlund B, Olander E, Jonsson $\mathbf{O}$ and Frennert S (2015) STS-inspired design to meet the challenges of modern ageing. Welfare technology as a tool to promote user driven innovations or another way to keep older users hostage? Technological Forecasting \& Social Change 93, 82-90.

Outila M and Kiuru H (2021) 'Picturephone in my home' - actor-network theory and Foucauldian discourse analysis on Northern Finnish older adults starting to use a video conferencing service. Journal of Technology in Human Services 39, 163-192.

Peek ST, Wouters EJ, van Hoof J, Luijkx KG, Boeije HR and Vrijhoef HJ (2014) Factors influencing acceptance of technology for aging in place: a systematic review. International Journal of Medical Informatics 83, 235-248.

Pirhonen J, Lolich L, Tuominen K, Jolanki O and Timonen V (2020) 'These devices have not been made for older people's needs' - older adults' perceptions of digital technologies in Finland and Ireland. Technology in Society 62, 101287.

Pols J (2017) Good relations with technology: empirical ethics and aesthetics in care. Nursing Philosophy 18, e12154.

Riikonen M, Mäkelä K and Perälä S (2010) Safety and monitoring technologies for the homes of people with dementia. Gerontechnology 9, 32-45.

Sanyal C, Stolee P, Juzwishin D and Husereau D (2018) Economic evaluations of eHealth technologies: a systematic review. PLOS ONE 13, e0198112.

Schou J and Hjelholt M (2019) Digitalizing the welfare state: citizenship discourses in Danish digitalization strategies from 2002 to 2015. Critical Policy Studies 13, 3-22.

Shulver W, Killington M, Morris C and Crotty M (2017) 'Well, if the kids can do it, I can do it': older rehabilitation patients' experiences of telerehabilitation. Health Expectations 20, 1201-1229.

Spann A and Stewart E (2018) Barriers and facilitators of older people's mHealth usage: a qualitative review of older people's views. Human Technology 14, 264-296.

Stokke R (2016) The personal emergency response system as a technology innovation in primary health care services: an integrative review. Journal of Medical Internet Research 18, e187.

Stolt R and Winblad U (2009) Mechanisms behind privatization: a case study of private growth in Swedish elderly care. Social Science \& Medicine 68, 903-911.

Stolt R, Blomqvist P and Winblad U (2011) Privatization of social services: quality differences in Swedish elderly care. Social Science \& Medicine 72, 560-567.

Strauss A and Corbin J (1994) Grounded theory methodology: an overview. In Denzin NK and Lincoln YS (eds), Handbook of Qualitative Research. Thousand Oaks, CA: Sage, pp. 273-285.

Sundberg L (2019) If Digitalization is the Solution, What is the Problem? Reading, UK: Academic Conferences International. Available at http://www.diva-portal.org/smash/get/diva2:1366965/FULLTEXT01. pdf.

Szebehely M (2014) Anhörigomsorg, förvärvsarbete och försörjning. I Lönsamt arbete-familjeansvarets fördelning och konsekvenser. Forskningsrapport till Delegationen för jämställdhet $i$ arbetslivet (SOU 2014:28). Stockholm: Fritze, pp. 131-158.

Szebehely M, Ulmanen P and Sand A (2014) Att ge omsorg mitt $i$ livet-hur påverkar det arbete och försörjning? Stockholm: Stockholms universitet, Institutionen för socialt arbete.

Tchalla AE, Lachal F, Cardinaud N, Saulnier I, Bhalla D, Roquejoffre A, Rialle V, Preux P-M and Dantoine T (2012) Efficacy of simple home-based technologies combined with a monitoring assistive center in decreasing falls in a frail elderly population (results of the Esoppe study). Archives of Gerontology and Geriatrics 55, 683-689.

Tsai HYS, Shillair R and Cotten SR (2017) Social support and 'playing around': an examination of how older adults acquire digital literacy with tablet computers. Journal of Applied Gerontology 36, 29-55.

Ulmanen P and Szebehely M (2015) From the state to the family or to the market? Consequences of reduced residential eldercare in Sweden. International Journal of Social Welfare 24, 81-92. 
United Nations (2020) World Population Ageing 2019 (ST/ESA/SER.A/444). Available at https://www.un. org/en/development/desa/population/publications/pdf/ageing/WorldPopulationAgeing2019-Report.pdf.

United Nations Economic Commission for Europe (2019) 2018 Active Ageing Index: Analytical Report. Available at https://www.unece.org/fileadmin/DAM/pau/age/Active_Ageing_Index/ECE-WG-33.pdf.

van Deursen AJAM and Helsper EJ (2015) The third-level digital divide: who benefits most from being online? In Robinson L, Cotten SR, Schulz J, Hale TM and Williams A (eds), Communication and Information Technologies Annual (Studies in Media and Communications). Bingley, UK: Emerald Group Publishing, pp. 29-53.

van Deursen AJAM and Van Dijk JA (2019) The first-level digital divide shifts from inequalities in physical access to inequalities in material access. New Media \& Society 21, 354-375.

Winstead V, Anderson WA, Yost EA, Cotten SR, Warr A and Berkowsky RW (2013) You can teach an old dog new tricks: a qualitative analysis of how residents of senior living communities may use the web to overcome spatial and social barriers. Journal of Applied Gerontology 32, 540-560.

Yusif S, Soar J and Hafeez-Baig A (2016) Older people, assistive technologies, and the barriers to adoption: a systematic review. International Journal of Medical Informatics 94, 112-116.

Zechner M and Valokivi H (2012) Negotiating care in the context of Finnish and Italian elder care policies. European Journal of Ageing 9, 131-140.

Zwijsen SA, Niemeijer AR and Hertogh CM (2011) Ethics of using assistive technology in the care for community-dwelling elderly people: an overview of the literature. Aging \& Mental Health 15, 419-427.

Cite this article: Valokivi H, Carlo S, Kvist E, Outila M (2023). Digital ageing in Europe: a comparative analysis of Italian, Finnish and Swedish national policies on eHealth. Ageing \& Society 43, 835-856. https://doi.org/10.1017/S0144686X21000945 